\title{
Effect of Hypericum perforatum on intraperitoneal adhesion formation in rats
}

\author{
Deniz Hızlı1 ${ }^{1}$ Fatih Hızlı², Aydın Köşüşs ${ }^{1}$, Saynur Yılmaz ${ }^{3}$, Nermin Köşüşs ${ }^{1}$, Hacer Haltaș ${ }^{4}$, \\ Hülya Dede ${ }^{3}$, Hasan Kafalı ${ }^{1}$
}

\begin{abstract}
'Department of Obstetrics and Gynecology, Fatih University Faculty of Medicine, Ankara, Turkey

2Department of Urology, Oncology Training and Research Hospital, Ankara, Turkey 3Department of Obstetrics and Gynecology, Zekai Tahir Burak Women's Health and Education Hospital, Ankara, Turkey

${ }^{4}$ Department of Pathology, Fatih University Faculty of Medicine, Ankara, Turkey
\end{abstract}

Submitted: 3 March 2012

Accepted: 29 November 2012

Arch Med Sci 2014; 10, 2: 396-400

DOI: 10.5114/aoms.2013.33070

Copyright $\odot 2014$ Termedia \& Banach

\section{Abstract}

Introduction: The aim of this study was to evaluate the efficacy of Hypericum perforatum for prevention of adhesion formation in rats.

Material and methods: Twenty-four female wistar rats underwent left uterine horn adhesion model. Rats were randomised into 4 groups. Group 1 (Control): Closure of abdominal incision without any agent administration. Group 2: Closure of incision after administration of intraperitoneal (i.p.) Ringer's lactate solution. Group 3: Closure of incision after administration of i.p. olive oil (diluent of H. perforatum). Group 4: Hypericum perforatum extract (Ecodab ${ }^{\oplus}$ ) was administered i.p. before the closure of incision. Fourteen days later, relaparatomy was performed and surgical adhesion scores, inflammation and fibrosis scores were noted. Groups were compared according to these scores.

Results: There was statistical significant difference between ringer's lactate group and olive oil group according to surgical adhesion score $(p=0.009)$. However, groups were not different according to inflammation and fibrosis scores $(p>0.05)$.

Conclusions: Despite antiinflammatory, antioxidants and antimicrobial properties of $H$. perforatum, our results revealed no positive effect of $H$. perforatum on the prevention of intraperitoneal adhesion formation.

Key words: Hypericum perforatum, intraperitoneal adhesion, prevention, rat, St. John's wort.

\section{Introduction}

Postoperative adhesions are an important problem and develop after almost all laparotomies [1]. Adhesions may cause severe clinical problems such as bowel obstruction, infertility and chronic pelvic pain [2-4].

Previous studies have evaluated different agents to reduce the incidence of intraperitoneal adhesions, including removal of fibrinous exudates by peritoneal lavage, use of proteolytic enzymes, anticoagulants, steroids, antihistamines, cytotoxic agents and use of substances such as olive oil or liquid paraffin $[3,5,6]$. However, the benefits of such methods in relation to intraperitoneal adhesions remain unclear. Moreover, despite strong efforts to reduce postoperative adhesions, $50 \%$ of patients still
Corresponding author: Deniz Hızlı

Fatih University Faculty of Medicine Department of Obstetrics and Gynecology Vatan Street No: 81 Demetevler 06530 Ankara, Turkey Phone: +90 5332484399 Fax: +90 3123462388 E-mail: denizhizli@yahoo.com 
develop significant adhesions [7-11]. Therefore, new approaches to this problem are warranted.

The sequence of adhesion formation has been reported as follows: tissue ischemia, inflammation, fibrin deposition, fibrin organization, collagen formation, and maturation with the formation of adhesions $[1,3,5,12]$. In an attempt to reduce the inflammatory reaction at the site of the peritoneal trauma, recent studies have focused on the use of anti-inflammatory drugs [3]. One anti-inflammatory agent which has not been studied for anti-adhesive efficacy previously is Hypericum perforatum.

Hypericum perforatum, commonly known as St. John's wort, is a yellow-flowering perennial herb grown in temperate and subtropical climates that has a long history of use as a medicinal plant for treating wounds and skin ailments, nerve problems, muscle pain, and mood disorders such as depression and anxiety [13-15]. Hypericum perforatum was first described by Robson in 1968 [16]. Many studies revealed this extract's positive effect on wound healing due to its anti-inflammatory, antimicrobial and antioxidant effects $[17,18]$. From this point of view, we decided to evaluate whether $H$. perforatum extract has a positive effect on postoperative adhesion formation in a rat model.

\section{Material and methods}

Twenty-four 4-5 month-old female Wistar rats weighing $250 \pm 20 \mathrm{~g}$ were housed in a climate-controlled (relative humidity of $40 \pm 5 \%$ and temperature of $21^{\circ} \mathrm{C}$ to $24^{\circ} \mathrm{C}$ ) animal care facility, with a 12 -hour light/dark cycle. Before and after surgical procedures, the animals were provided with standard rat chow and water, ad libitum. After adaptation, the animals were randomly assigned to 4 different groups, each consisting of 6 rats.

Anesthesia was induced by injection of ketamine (45 mg/kg i.m. of Ketalar; Eczacibasi, Istanbul, Turkey) and xylazine ( $5 \mathrm{mg} / \mathrm{kg}$ ) anesthesia. The surgical procedures were performed under sterile conditions. Before the surgery, gloves were washed extensively with saline to remove any particles of powder. All operations were performed by the same author who was blinded to the treatment group. The rats were randomly assigned and not sequentially operated on in order to minimize bias. The operation was limited to $10 \mathrm{~min}$ for each rat and antibiotic prophylaxis was not given.

A 3-cm vertical midline incision was performed and both uterine horns were exposed. Punctate serosal hemorrhages were generated by scraping with a No. 15 scalpel blade until petechial bleeding emerged at the abdominal sidewall and antimesenteric surface of the left uterine horn to create adhesions. The abdominal incision was closed in two layers using a simple interrupted 4-0 polyglactin 910 suture for the peritoneum-fascia and for the skin.
Prior to closure of the abdominal incision, the following agents were given in the abdominal cavity.

Group 1 (Control): Closure of abdominal incision without any agent administration. Group 2 (Ringer's lactate): $2 \mathrm{ml} /$ rat intraperitoneal (i.p.) of Ringer's lactate solution was administered before closure of the incision. Group 3 (Olive oil): $2 \mathrm{ml} / \mathrm{rat}$ of olive oil was administered to the rats i.p. (diluent of $H$. perforatum). Group 4 (H. perforatum): $2 \mathrm{ml} / \mathrm{rat} H$. perforatum extract (Ecodab $\left.{ }^{\circledR}\right)$ was administered i.p.

The second laparotomy with a U-shaped incision was performed 14 days after the first surgery. Adhesions were scored according to the clinical adhesion scoring system of Leach et al. [19] by the same author who performed the first laparotomy. The author was blind to which group was being evaluated. A total score of 10 was possible. Adhesions to the uterine horn defect were scored as follows: $0=$ no uterine adhesion; $1=1-25 \%$ involvement; $2=26-50 \% ; 3=51-75 \%$; and $4=76-100 \%$. Adhesions were further characterized on gross examination for severity as follows: 0 = no adhesions; 1 = filmy avascular; 2 = vascular or opaque; 3 = cohesive attachment of uterine horns to each other or other abdominal structures. The degree of adhesion formation was evaluated with the following adhesion scores: 0 = no adhesions; 1 = if the adhesion was separated from tissue with gentle traction; 2 = requiring moderate traction; and $3=$ requiring sharp dissection.

Histopathological examination was performed by one investigator. Adhesion-carrying tissues were excised en-bloc and fixed in a 10\% buffered formaldehyde solution. The tissue samples were embedded in paraffin wax, cut into $5 \mu \mathrm{m}$ sections and stained with hematoxylin-eosin and Masson's trichrome. Inflammation was scored as follows: 0 - no inflammation; 1 - presence of giant cells, occasional lymphocytes and plasma cells; 2 - presence of giant cells, plasma cells, eosinophils and neutrophils; and 3 - presence of many inflammatory cells and microabscesses. The amount of fibrosis was scored as: 0 = no fibrosis; 1 = minimal, loose; 2 = moderate; and 3 = florid dense.

The experimental procedures in the present study were approved by the Gazi University School of Medicine Ethics Committee (No: 11.001) and supported by the Scientific Research Fund of Fatih University under the project number P53011001_G 1471.

\section{Statistical analysis}

Statistical analysis was performed using the Statistical Package for Social Science (SPSS for Windows, Version 15.0, Chicago, Illinois). Kruskal-Wallis and Mann-Whitney $U$ tests corrected with Bonferroni were used. A value of $p<0.05$ was regarded as significant. 
Table I. Median surgical, inflammation and fibrosis score of groups

\begin{tabular}{|lccccc|}
\hline Variables & Control & Ringer & Olive oil & SJW & Value of $p$ \\
\hline Surgical score & $8(2)$ & $8(1.5)$ & $5.5(3.25)$ & $4(1.5)$ & $0.009+$ \\
\hline Inflammation score & $1(1)$ & $2(1)$ & $1.5(1.25)$ & $2(0.25)$ & 0.035 \\
\hline Fibrosis score & $1(1.25)$ & $1(1.25)$ & $1.5(1.25)$ & $2(1.25)$ & 0.221 \\
\hline
\end{tabular}

SJW - St. John's wort (Hypericum perforatum), $p<0.0125$ regarded as statistically significant (Kruskal-Wallis and Mann-Whitney U tests corrected with Bonferroni were used). ${ }^{\dagger}$ There is a statistically significant difference between olive oil and Ringer group

Table II. Comparison of the adhesion, inflammation and fibrosis score of groups

\begin{tabular}{|lccc|}
\hline Variables & & Values of $p$ \\
\cline { 2 - 4 } & Surgical adhesion grade & Inflammation & Fibrosis \\
\hline Sham vs. ringer & 0.310 & 0.026 & 0.240 \\
\hline Sham vs. olive oil & 0.026 & 0.589 & 0.310 \\
\hline Sham vs. SJW & 0.065 & 0.041 & 0.065 \\
\hline Ringer vs. olive oil & 0.009 & 0.180 & 0.937 \\
\hline Ringer vs. SJW & 0.065 & 0.699 & 0.485 \\
\hline Olive oil vs. SJW & 0.818 & 0.240 & 0.394 \\
\hline
\end{tabular}

SJW - St. John's wort (Hypericum perforatum)

\section{Results}

Median surgical adhesion scores of the groups are presented in Table I. Adhesion score was lower in the olive oil group when compared to the Ringer's lactate group and control group and there was a statistically significant difference between the Ringer's lactate group and olive oil group $(p=0.009)$. Rats treated with $H$. perforatum had lower surgical adhesion scores when compared to the olive oil group; however, the difference was not significant $(p=0.8)$ (Table II). Differences between each group according to surgical adhesion score are shown in detail in Table II. Appearance of intra-abdominal adhesion is shown in Figure 1.

Median inflammation and fibrosis scores of each group are presented in Table I. The histological appearances of fibrosis and inflammation are shown in Figure 2. The olive oil group had a lower inflammation score when compared to Ringer and $H$. perforatum groups but the difference between groups was not statistically significant
(Table II). Similarly, no difference was detected between groups according to the fibrosis score.

\section{Discussion}

In the present study, $H$. perforatum was evaluated for efficacy in the prevention of postoperative adhesion formation in a rat adhesion model. The results showed that administration of $H$. perforatum was not effective to prevent or reduce intraabdominal adhesions.

Postoperative adhesions, formed after abdominal surgery, develop in up to $95 \%$ of patients and can lead to serious complications including small bowel obstruction, infertility, dyspareunia, difficulty with future operations, and possible chronic pelvic pain [1, 20, 21].

Intra-abdominal adhesion formation is initiated by the increase in vascular permeability and secretion of fibrin-rich exudate which are triggered by peritoneal injury. Under normal conditions, these
A

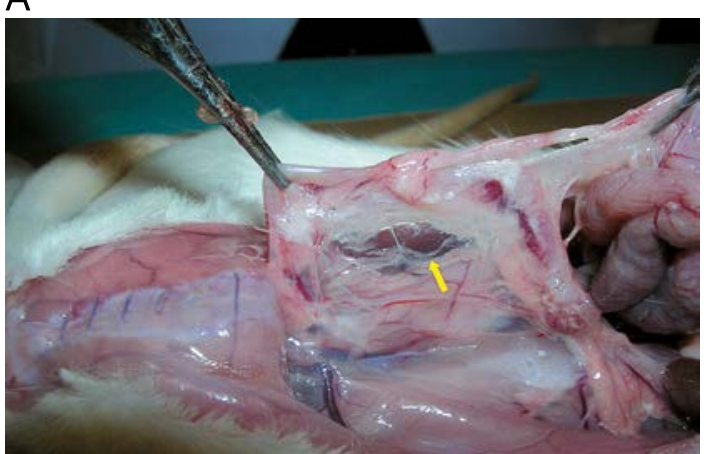

B

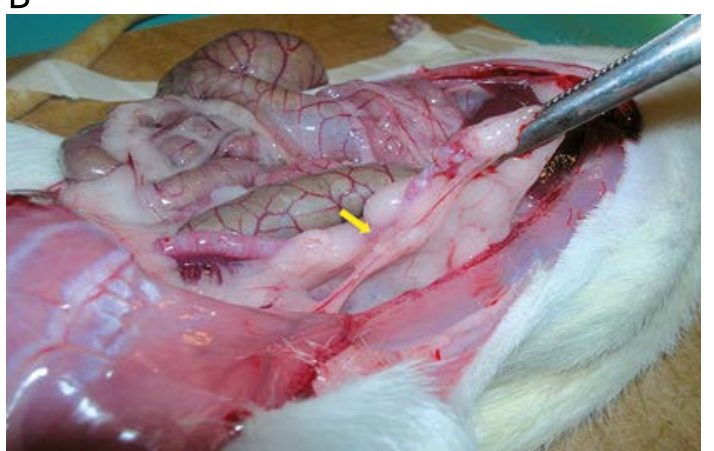

Figure 1. The appearance of dense intra-abdominal adhesions in rat 
A

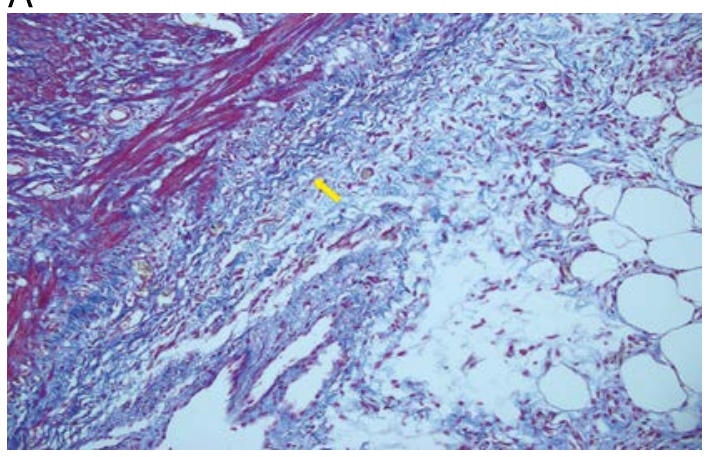

B

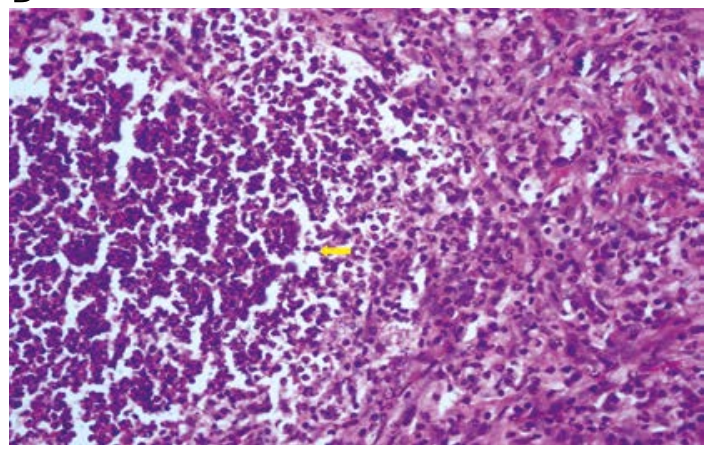

Figure 2. Histologic appearance of fibrosis (A) (Masson trichrome stain 200x) and inflammation (B) (hematoxylin and eosin stain 400x)

bands are resolved by fibrinolysis. However, under ischemic or inflammatory conditions, the peritoneal fibrinolytic system is suppressed and these bands are infiltrated with inflammatory cells and fibroblasts, which create dense adhesions. Studies that aim to prevent adhesions have focused on the prevention of various steps of this physiopathological process. Antiinflammatory agents, antioxidants, anticoagulants, fibrinolytics and bioabsorbable physical barriers have been used in this regard [3, 22]. Despite positive reports, there is still no consensus about this issue $[23,24]$.

Experimental studies showed that $H$. perforatum has antiinflammatory, antioxidant and antimicrobial properties $[17,18,25,26]$. As the physiopathological process of adhesion formation is considered, H. perforatum has many characteristics which make it potentially suitable in the prevention of peritoneal adhesions. From this point of view, we hypothesized that $H$. perforatum may prevent or reduce postoperative intra-abdominal adhesion formation.

Hypericum perforatum has been used as a medicinal plant for more than 2000 years. The antiinflammatory effect of $H$. perforatum was attributed to quercetin, 13,II8-biapigenin and hypericin inside the extract [27]. In vitro hypericin has been shown to inhibit tumor necrosis factor $\alpha$-induced activation of the transcription factor NF- $\kappa B$ that is involved in the immunological and inflammatory response [28]. It was reported that the anti-inflammatory effect of $H$. perforatum extract appeared to be, at least partly, a consequence of inhibition of $\mathrm{NF}-\kappa \mathrm{B}$ by hypericin. Also hypericin significantly and dose-dependently inhibited the release of arachidonic acid and, as a result, of leukotriene B4, and strongly inhibited interleukin $1 \alpha(\mathrm{IL}-1 \alpha)$, possibly by inhibiting protein kinase $\mathrm{C}[29,30]$. Interleukin $1 \alpha$ is well known as a potent factor in mediating inflammation and fever.

Hypericin also possesses antioxidant activity, acts as a free-radical scavenger [31], inhibits the formation of interleukin (IL)-1a and IL-12 and inhibits the release of arachidonic acid from phospholipids and its metabolism through 5- and 12-lipoxygenase pathways [29].

Moreover, in 2000, Schempp et al. reported the immunomodulatory effect of a $\mathrm{H}$. perforatum ointment, which reduced stimulation of $\mathrm{T}$ lymphocytes by epidermal cells after application to skin [32].

Some animal studies have reported a benefit from Ringer's lactate in preventing adhesions [33, 34]. It has been stated that Ringer's lactate prevents adhesion formation by mechanical cleaning of blood clots at the surgical site [35]. Also it is supposed that the presence of a high volume of the solution in the abdominal cavity separates raw peritoneal surfaces and thus prevents adhesion formation [36]. On the other hand, in two clinical studies, the effect of dextran solution on postoperative adhesion formation was compared with that of Ringer's lactate solution [36, 37]. In both studies, no beneficial effect of Ringer's lactate was found, and many of the patients treated with Ringer's lactate had more adhesions at the time of second examination laparoscopy than before the initial procedure. In the present study, the peritoneal adhesions treated with Ringer's lactate also did not show a significant decrease when compared to the control group.

To the best our knowledge there is no study which has evaluated the efficacy of $H$. perforatum for prevention of adhesion formation. From this point of view the present study is the first study in which the anti-adhesive role of $H$. perforatum has been studied. Despite anti-inflammatory, antioxidant and antimicrobial properties of $H$. perforatum, no positive effect of $H$. perforatum on the prevention of intraperitoneal adhesion formation was found in the present study. This finding suggests that other mechanisms of adhesion formation beside ischemic or inflammatory conditions may be responsible for adhesion formation after surgery. More detailed studies are needed on this topic and future studies should clarify the exact pathophysiological mechanisms of adhesion formation to develop safe and effective agents to achieve maximum efficacy in the prevention of adhesions. 


\section{Acknowledgments}

This study was supported by the Scientific Research Fund of Fatih University under the project number P53011001_G 1471.

\section{References}

1. Menzies D, Ellis H. Intestinal obstruction from adhesionshow big is the problem. Ann R Coll Surg Eng 1990; 72: 60-3.

2. Parker MC, Wilson MS, Menzies D, et al. Colorectal surgery: the risk and burden of adhesion-related complications. Colorectal Dis 2004; 6: 506-11.

3. Liakakos T, Thomakos N, Fine PM, Dervenis C, Young RL Peritoneal adhesions: etiology, pathophysiology, and clinical significance. Recent advances in prevention and management. Dig Surg 2001; 18: 260-73.

4. Becker JM, Dayton MT, Fazio VW, et al. Prevention of postoperative abdominal adhesions by a sodium hyaluronatebased bioresorbable membrane: a prospective, randomized, double-blind multicenter study. J Am Coll Surg 1996; 183: 297-306

5. Hickey MJ, Di Zeraga GS. Recent advances in adhesion prevention. Contemp Obstet Gynecol 1990; 35: 14-6.

6. Holmdahl L, Risberg B, Beck DE, et al. Adhesions: pathogenesis and prevention panel discussion and summary. Eur J Surg 1997; 163 (Suppl. 577): 56-62.

7. Kaptanoglu L, Kucuk HF, Yegenoglu A, et al. Effects of seprafilm and heparin in combination on intra-abdominal adhesions. Eur Surg Res 2008; 41: 203-7.

8. Avsar AF, Avsar FM, Sahin M, Topaloglu S, Vatansev H, Belviranli $M$. Diphenhydramine and hyaluronic acid derivates reduce adnexal adhesions and prevent tubal obstructions in rats. Eur J Obstet Gynecol Reprod Biol 2003; 106: 50-4.

9. Kesting MR, Loeffelbein DJ, Steinstraesser L, et al. Cryopreserved human amniotic membrane for soft tissue repair in rats. Ann Plast Surg 2008; 60: 684-91.

10. Corrales F, Corrales M, Schirmer CC. Preventing intraperitoneal adhesions with vitamin $\mathrm{E}$ and sodium hyaluronate/ carboxymethylcelulose. A comperative study in rats. Acta Cir Bras 2008; 23: 36-41.

11. Kucuk HF, Kaptanoglu L, Kurt N, et al. The role of simvastatin on postoperative peritoneal adhesion formation in an animal model. Eur Surg Res 2007; 39: 98-102.

12. Gomel V, Urman B, Gürgan T. Pathophysiology of adhesion formation and strategies for prevention. J Reprod Med 1996; 41: 35-41.

13. Charrois TL, Sadler C, Vohra S. Complementary, holistic, and integrative medicine: St. John's wort. Pediatr Rev 2007; 28: 69-72.

14. Castro FC, Magre A, Cherpinski R, et al. Effects of microcurrent application alone or in combination with topical Hypericum perforatum $\mathrm{L}$. and Arnica montana $\mathrm{L}$. on surgically induced wound healing in Wistar rats. Homeopathy 2012; 101: 147-53.

15. Samadi S, Khadivzadeh T, Emami A, Moosavi NS, Tafaghodi M, Behnam HR. The effect of Hypericum perforatum on the wound healing and scar of cesarean. J Altern Complement Med 2010; 16: 113-7.

16. Robson NKB. Hypericum L. In: Flora Europaea. Webb DA. Cambridge University Press, London 1968; 261-6.

17. Schempp CM, Muller KA, Winghofer B, Schopf E, Simon JC. St. John's wort (Hypericum perforatum L.). A plant with relevance for dermatology. Hautarzt 2002; 53: 316-21.

18. Zdunić G, Godevac D, Milenković M, et al. Evaluation of Hypericum perforatum oil extracts for an antiinflammatory and gastroprotective activity in rats. Phytother Res 2009; 23: 1559-64.
19. Leach RE, Burns JW, Dawe EJ, SmithBarbour MD, Diamond MP. Reduction of postsurgical adhesion formation in the rabbit uterine horn model with use of hyaluronate/carboxymethylcellulose gel. Fertil Steril 1998; 69: 415-8.

20. Ellis H, Moran BJ, Thompson JN, et al. Adhesion-related hospital readmissions after abdominal and pelvic surgery: a retrospective cohort study. Lancet 1999; 353: 1476-80.

21. Coleman MG, McLain AD, Moran BJ. Impact of previous surgery on time taken for incision and division of adhesions during laparotomy. Dis Colon Rectum 2000; 43: 1297-9.

22. DiZerega GS. Peritoneal surgery. New York: Springer, 2000. Ellis, H. Adhesions. The early history. Hospital Medicine 2004; 65: 328-9.

23. Ellis $\mathrm{H}$. Intraabdominal and postoperative peritoneal adhesions. J Am Coll Surgeon 2005; 200: 643-50.

24. Ellis H. Postoperative intra-abdominal adhesions: a personal view. Colorectal Dis 2007; 9: 3-8.

25. Mattace Raso G, Pacilio M, Di Carlo G, Esposito E, Pinto L, Meli R. In-vivo and in-vitro anti-inflammatory effect of Echinacea purpurea and Hypericum perforatum. J Pharm Pharmacol 2002; 54: 1379-83.

26. Abdel-Salam OM. Anti-inflammatory, antinociceptive, and gastric effects of Hypericum perforatum in rats. Sci World 2005; 5: 586-95.

27. Sosa S, Pace R, Bornancin A, et al. Topical anti-inflammatory activity of extracts and compounds from Hypericum perforatum L. J Pharm Pharmacol 2007; 59: 703-9.

28. Baeuerle PA, Henkel T. Function and activation of NF-kappaB in the immune system. Annu Rev Immunol 1994; 12: 141-79.

29. Panossian AG, Gabrielian V, Manvelian K, Jurcic K, Wagner H. Immunosuppressive effects of hypericin on stimulated human leukocytes: inhibition of the arachidonic acid release, leukotriene B4 and interleukin-1 (production, and activation of nitric oxide formation). Phytomedicine 1996; 3: 19-28.

30. Takahashi I, Nakanishi S, Kobayashi E, Nakano H, Suzuki K, Tamaoki T. Hypericin and pseudohypericin specifically inhibit protein kinase C: possible relation to their antiretroviral activity. Biochem Biophys Res Commun 1989; 165: 1207-12.

31. Cakir A, Mavi A, Yildirim A, Duru ME, Harmandar M, Kazaz C. Isolation and characterization of antioxidant phenolic compounds from the aerial parts of Hypericum hyssopifolium L by activity-guided fractionation. J Ethnopharmacol 2003; 87: 73-83.

32. Schempp CM, Winghofer B, Lüdtke R, Simon-Haarhaus B, Schöpf E, Simon JC. Topical application of St John's wort (Hypericum perforatum L.) and of its metabolite hyperforin inhibits the allostimulatory capacity of epidermal cells. Br J Dermatol 2000; 142: 979-84.

33. Caballero J, Tulandi T. Effects of Ringer's lactate and fibrin glue on postsurgical adhesions. J Reprod Med 1992; 37: 141-3.

34. Tulandi T. Effects of ringer's lactate on postsurgical adhesion. Progress in Clinical and Biological Research 1993; 381: 149-53.

35. Pfeffer WH. Adjuvants in tubal surgery. Fertil Steril 1980; 33: 245-56.

36. Hellebrekers BWJ, Trimbos-Kemper GCM, van Blitterswijk CA, Bakkum EA, Trimbos JB. Effects of five different barrier materials on postsurgical adhesion formation in the rat. Human Reprod 2000; 15: 1358-63.

37. Jansen R. Failure of intraperitoneal adjuncts to improve the outcome of pelvic operations in young women. Am J Obstet Gynecol 1985; 153: 363-71. 